\title{
QUEVEDO Y LAS TRAVESURAS DEL MITO ${ }^{1}$
}

\author{
SAMUEL FASQUEL \\ Université de Lille III
}

La parodia de los diversos cauces de la lírica clásica y renacentista figura entre los procedimientos que produjeron los más granados frutos de la poesía burlesca. Buen ejemplo de ello es el epilio burlesco², cuyo éxito en el siglo XVII cuaja a raíz de la difusión

\section{Recibido: 30-XI-2009 Aceptado: 3-II-2010}

2 «El epyllion no es sino una epopeya de materia mitológica en miniatura, designada habitualmente en el campo de la hispanística como fábula mitológica. El epilio castellano, como el epilio alejandrino de Mosco o Calímaco, al igual que los epilios de Catulo u Ovidio, se caracteriza por la visión juguetona de los viejos mitos, por la combinación lúdica de las formas, por la recurrencia de complejos mecanismos alusivos y por la miniaturización de algunos paradigmas literarios. Otros rasgos muy frecuentes en tal microgénero serían la sobredimensión de los elementos descriptivos con respecto a los segmentos narrativos, la inclinación hacia los temas románticos antes que hacia los propiamente heroicos y la contaminación con otras modalidades poéticas (como puede ser la elegía)». J. Ponce, «La poesía de Miguel Colodrero de Villalobos: consideraciones en torno al epilio y los motivos del retiro en la naturaleza», en J. Roses (ed.), Góngora Hoy. VI. Actas del foro de debate Góngora Hoy celebrado en la Diputación de Córdoba: Góngora y sus contemporáneos : de Cervantes a Quevedo, Diputación de Córdoba, 2004, 145-198, pág. 148. 
de la gongorina Fábula de Píramo y Tisbe. La coexistencia de las versiones graves y de sus contrafacta burlescos es ya de por sí significativa de la eficacia poética que se reconocía a unos grandes mitos cuyo sentido moral o alegórico se había procurado explicar. En el presente trabajo propongo estudiar cómo el locutor burlesco quevediano se mofa de tales explicaciones y les sustituye una interpretación traviesa del mito.

Me centraré fundamentalmente en tres poemas publicados en la musa Talía del Parnaso Español de Quevedo, un poeta que, como declara Susana Guerrero Salazar, si bien no escribió muchos poemas que recrearan íntegramente una fábula, hizo un uso copioso de los mitos ${ }^{3}$. Propongo confrontar lo que puede considerarse un discurso sobre los mitos con dos parodias de fábulas mitológicas amorosas, Califica a Orfeo para idea de maridos dichosos y Hero y Leandro en paños menores (POC, 700, 765, 771) ${ }^{4}$. Mi objetivo es demostrar que, en estos poemas, la parodia quevediana radica en una puesta a distancia de las interpretaciones del sentido de los mitos, en particular sus interpretaciones alegóricas. El narrador considera tales interpretaciones erróneas porque descansan en un conocimiento parcial o equivocado del mito, y por lo tanto el valor paradigmático que se pretende dar a éste carece de fundamento. Intentaré hacerlo estudiando el discurso suscitado por los mitos, la rectificación de las interpretaciones que se da a las empresas de Orfeo y Leandro, y, por fin, procuraré situar este tipo de parodias en la poética de Quevedo.

\section{VERDAD Y MENTIRA DE LOS MITOS}

Desde los primeros capítulos de su obra magna, Natale Conti lamentaba que nadie se hubiera molestado en escudriñar el sentido de las fábulas y la doctrina en ellas ejemplificada. El lector que no repara en la utilidad de los relatos mitológicos es comparable con un niño que escucha cuentos de viejas sin ahondar en el sentido que puede cifrarse en una ficción amena ${ }^{5}$. En el mismo orden de cosas, nada más empezar su Philosofía secreta donde debajo de historias fabulosas se contiene mucha doctrina provechosa a todos estudios (1585), Pérez de Moya puntualiza su concepción de la fábula. Al sentido literal o histórico cabe añadirle otros varios que pueden agruparse bajo el rótulo de

3 S. Guerrero Salazar, La parodia quevediana de los mitos. Mecanismos léxicos, Universidad de Málaga, 2002, pág. 95.

4 Citaré a partir de la edición de J. M. Blecua (Quevedo, Poesía original completa, Planeta, Barcelona, 1999, en adelante POC). J. Crosby editó los poemas de Orfeo y Hero y Leandro (Quevedo, Poesía varia, Cátedra, Madrid, 1996, págs. 468-69 y 476-486).

5 N. Conti, Mitología, ed. R. M. Iglesias Montiel y M. C. Álvarez Morán, Universidad de Murcia, 1988, capítulos I y II. Las editoras, pág. 47, precisan que Conti «olvida mencionar las obras que en este campo le han precedido, como son la G. D. [Genealogía de los dioses paganos] de Boccaccio y la Multiplex historia de Gyraldi». 
alegóricos ${ }^{6}$. La fábula tiene un valor pedagógico, ya que, si bien «toda fábula se funda en un razonamiento de cosas fingidas», su aparente verosimilitud debe «inducir a los lectores a muchas veces leer y saber su escondida moralidad y provechosa doctrina» ${ }^{7}$. El sentido moral del mito de Orfeo, por ejemplo, radica en la declaración del castigo y la desgracia que amenazan a cualquiera que se deje llevar por «los deleites o apetitos naturales», encarnados por Eurídice.

Ahora bien, para el locutor burlesco de Quevedo, este valor alegórico de los mitos a menudo descansa en bases deleznables que lo invalidan ${ }^{8}$. No se debe atribuir mucha credibilidad a estas interpretaciones porque se fundan en algunos casos en una mentira, y en otros en una lectura ingenua del mito. Evidentemente, no se trata de decidir si Ovidio o Museo fueron o no dos geniales autores de patrañas, sino de jugar con los conocimientos del lector y su familiaridad con el universo de Las Metamorfosis y el Poema de Hero y Leandro. El distanciamiento con la mitología o la paradoxografía se transparenta de dos modos. El locutor puede, sencillamente, negar la verosimilitud del mito, oponer al prestigio del saber humanista la autoridad de la experiencia. Es precisamente lo que pasa en el romance 700, que se burla de la fe en el Fénix, el Pelícano, el Basilisco o el Unicornio. El locutor también puede contemplar los mitos afirmando que procede desconfiar de su exégesis más frecuente, ya que las motivaciones y características de los héroes más corrientemente aducidas suelen ser erróneas. El poema de Hero y Leandro (POC, 771), así como el de Orfeo (POC, 765), deben leerse a la luz de este argumento de la interpretación equivocada o ingenua.

6 «De cinco modos se puede declarar una fábula, conviene a saber: literal, alegórico, anagógico, tropológico, y físico o natural [...] Y es de advertir que los tres sentidos últimos, puesto que sean nombrados con diversos nombres, todavía se pueden llamar alegóricos, porque, como hemos dicho, alegoría dicen a lo que es diverso del sentido histórico o literal». J. Pérez de Moya, Philosofía secreta, ed. Carlos Clavería, Cátedra, Madrid, 1995, págs. 69-70. Es de gran interés la reciente contribución de G. Serés, «Antecedentes exegéticos de la Filosofía secreta de Juan Pérez de Moya (1585)», en C. Courderc y B. Pellistrandi (ed.), «Por discreto y por amigo». Mélanges offerts à Jean Canavaggio, Collection de la Casa de Velázquez (88), Madrid, 2005, págs. 633-648. Carvallo, en su Cisne de Apolo, dedica varios capítulos a la cabal interpretación de la fábula. Sobre sus varios sentidos, consultar el capítulo 7 del Diálogo Primero.

7 Pérez de Moya, loc. cit., pág. 65. Este razonamiento de Pérez de Moya lo retoma casi textualmente Las metamorfoses, o transformaciones de Ovidio, en quince Libros, buelto en castellano, Madrid, 1664. A costa de Antonio del Ribero Rodríguez, Mercader de Libros, f. 9r. Precisa que la «provechosa doctrina» «va fundada en manifestar las condiciones, y costumbres de los hombres, a los quales conforme a sus obras, apropian a diversas propiedades, y naturaleza de cosas, sublimando los virtuosos, y vituperando los vicios. Y assi deve el prudente Lector considerar este principio, para sacar algun fruto de la letura deste Poeta, y por la mayor parte de todos los demas». Al lector le corresponde, pues, la ardua tarea de determinar cuál es el sentido alegórico de la fábula.

8 Guerrero Salazar, op. cit., pág. 33, declara que Quevedo «[...] cuestiona [...] la sublimación esteticista propia del Renacimiento y la funcionalidad moralizadora propia del Barroco, colocando, como contrapartida, el caudal mitológico al servicio de la burla y la ironía». 


\subsection{Del púlpito a la despensa}

Lo que interesa al locutor burlesco en el Fénix ${ }^{9}$, el Basilisco y el Unicornio, son las propiedades fabulosas que se les atribuyen : perpetuo renacimiento del ave oriental, carácter mortal de la mirada y el soplo del basilisco, «inmensa virtud» del cuerno del Unicornio. En el caso del Pelícano, se demora en la dimensión alegórica que hace del ave una «fábula de la piedad». Esta fuerte caracterización de dichas criaturas míticas favorece la multiplicación de apodos que glosan los atributos de cada uno. El poeta puede así calificar a la vistosa Fénix de «avechucho de matices», o de «eterna hermafrodita», al sangriento Pelícano de «pájaro disciplinante» o «avechucho del martirio», y declarar a propósito del Basilisco : «y no hay en Galicia pueblo / que tenga tan malas vistas». Para el locutor burlesco, el carácter maravilloso atribuido a estos seres míticos es el indicio de su inexistencia, ya que los relatos que los describen no resisten la prueba de la experiencia. Por ello Quevedo afirma que el Fénix sólo aparece en las coplas y las mentiras (La Fénix, vv. 11-12), y que el Pelícano no existe más que «en los púlpitos y libros» o en los conceptos de los poetas que aprovechan su consonante (El Pelícano, vv. 8, 33 y 41). La existencia de estas dos aves la niega tajantemente desde la dedicatoria a Juan de la Sal, obispo cuyo apellido entra ingeniosamente en la red semántica de la mesa y la comida, omnipresente en las seis primeras cuartetas. Con ella el locutor opone las aves míticas, las de Plinio y los libros, a las aves reales, las que la lengua y las muelas pueden probar, las que se encuentran en las despensas. La misma oposición entre autoridad de la paradoxografía y fe en la experiencia de la mesa da pie a la siguiente cuarteta del romance sobre el Pelícano (vv. 13-16):

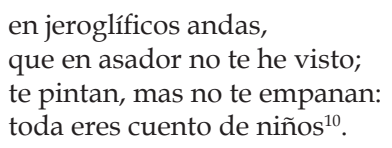

Del mismo modo que, desde Plinio, se dudaba de la existencia de un ave nunca vista como el Fénix ${ }^{11}$, el locutor burlesco pretende determinar si se debe o no dar fe

9 Varios ejemplos de recurso a la imagen del Fénix en la poesía burlesca de Quevedo se encuentran en Guerrero Salazar, op. cit., pág. 42, n. 46.

10 V. Nider, «La Fénix», La Perinola, 6, 2002, 161-180, págs. 166-167, comenta esta oposición entre existencia meramente literaria y experiencia de la mesa.

11 Pantaleón de Ribera evoca «el Fénix fragoso, / ave rara de la tierra, / y que no vimos nosotros». (El Fénix, vv. 30-32). En nota a su edición de Pantaleón, J. Ponce Cárdenas cita y traduce el texto de Plinio (Nat. Hist., X, 2, 3) en el que el autor latino expresa sus dudas sobre la existencia de dicha ave (A. Pantaleón de Ribera, Obra selecta, Universidad de Málaga, 2003, pág. 234). Baltasar de Vitoria, en la Primera parte del Teatro de los Dioses de la Gentilidad, cita varias opiniones sobre el particular, y concluye: «La mayor noticia ocular que del ave Fénix se ha tenido, es que en tiempo de el Emperador Claudio, se vio en Egypto, y no se ha visto más: ni nuestros Españoles que han atravessado aquellas regiones de Arabia, y Persia, en nuestros tiempos han hallado nuevas ningunas de tal ave». La cita se encuentra en la página 614 de la edición publicada en Madrid en 1676. Entre las «Premáticas y ordenanzas que se han 
a la existencia del basilisco a partir de los testimonios visuales recogidos sobre dicha criatura, es decir otra vez a partir de la experiencia:

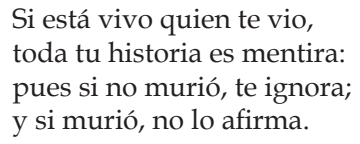

Este razonamiento de apariencia silogística se construye en torno a una prótasis, una apódosis y una justificación. Las palabras situadas al final de cada verso (vio, mentira, ignora, afirma) sugieren lo que el silogismo muestra. Los que afirman que vieron el basilisco mienten porque, si fuese cierto lo que cuentan, debieran haber muerto. El lector comprende que la historia es una mentira porque sólo puede originarse en testimonios falsos. No existe la posibilidad de un testimonio verdadero sobre el basilisco, ya que el testigo eventual no puede estar vivo. Por lo tanto, no hay ningún relato sobre el basilisco que pueda descansar en una experiencia personal y, por ende, ser verosímil. En la cuarteta siguiente, el locutor imagina una hipótesis que permita dar alguna credibilidad a los testimonios visuales sobre el ser fabuloso : la existencia de un basilisco ciego, y por lo tanto inocuo para quienes lo vieron.

La experiencia también es lo que permite dudar de la existencia del Unicornio. Notemos que en este último caso se acepta la posibilidad que exista el animal en la India, pero se rechaza para las tierras conocidas del locutor, menos transitadas por el Unicornio que por los «muchicuernos». Frente a lo que se cuenta (El Unicornio, vv. 1, $5,17,37,42,45,50)$, el locutor opone lo que caracteriza el «uso del tiempo» en «nuestro pueblo» (vv. 14 y 46), es decir una multitud de cornudos, que, de haber inventado semejante animal, no hubiesen tenido que escatimar sus cuernos y dejarle con tan sólo uno:

\footnotetext{
No te inventaron maridos: que no son tan avarientos; pues por añadirte otro, no empobrecieran más presto.
}

Para el locutor deQuevedo, estos cuatro animales pecan por orgullo porque, como los cortesanos altivos, pretenden encaramarse encima de los demás. Evidentemente, el locutor no juzga el Fénix o el Pelícano comparándolos con otras criaturas fabulosas sino con las aves corrientes, las del corral. La perspectiva pragmática del locutor burlesco le

\footnotetext{
de guardar en la Real Academia del Buen Retiro», concebidas para la Academia Burlesca de 1637, viene una que manda «que se ponga perpetuo silencio» en la memoria del Fénix, por ser ave sin provecho y mera superstición, y por ser «finalmente sospechosa, pues no tiene abuelo que no haya sido quemado». «Dios se lo perdone a Claudiano, que celebró esta necedad imaginada para que todos los poetas pecasen en él» (M. T. Julio (ed.), Academia burlesca que se hizo en Buen Retiro a la Majestad de Filipo Cuarto el Grande de 1637, Iberoamericana-Vervuert, Madrid-Frankfurt, 2007, págs. 58-60).
} 
lleva a considerar que éstas valen más que los animales míticos, ya que de algo sirven al hombre que las come. Es este punto de vista el que justifica en parte la agresividad de la reprensión (léase al respecto la última cuarteta de los romances sobre el Fénix, el Pelícano y el Basilisco). En este romance, Quevedo socava la verosimilitud del universo mítico oponiéndole la irrebatible evidencia de la experiencia ${ }^{12}$. Esta inverosimilitud neutraliza o invalida por anticipación y en sus bases mismas las interpretaciones morales que pudieron darse, por ejemplo, en la emblemática ${ }^{13}$. Se trata de un primer tipo de distanciamiento literario con los mitos.

\subsection{La interpretación equivocada}

El segundo tipo de distanciamiento evocado contempla directamente la reinterpretación de los mitos, y puede tomar la forma de la inversión del motivo clásico. El locutor considera que la exégesis de los textos mitológicos anda por caminos extraviados, y que la motivación de los héroes no es tan pura como se cree. Si Orfeo, al bajar a los Infiernos, canta, es por la alegría que llena a cualquier viudo por fin librado de su mujer. Por la misma razón se puede considerar que pudo volver la cabeza y mirar a Eurídice adrede, para separarse otra vez de ella (vv. 29-32). Pero la interpretación del poema quevediano es deficiente si nos conformamos con esto. Si la viudez de Orfeo le regocija, ¿ por qué bajar a los Infiernos ? Si al final determina efectivamente separarse otra vez de Eurídice, ¿ por qué haber bajado ? No creo exagerado suponer que lo que lleva a Orfeo no es el amor sino la lujuria, lo que el Siglo de Oro llama, con los romanos, la Venus. Por eso está tan contento cuando baja a los Infiernos, y por eso le resulta igual de difícil tanto el hecho de no mirar a Eurídice como el de llevarla definitivamente (v. 24). Procede, quizás, entender algo más de lo que dijeron Ovidio y Virgilio en los versos que indican que Orfeo iba delante de Eurídice «al subir», y que los hombres, «al bajar», se dejan conducir de las mujeres ${ }^{14}$. No olvidemos que Pérez de Moya interpretaba la debilidad de Orfeo como una prueba de que «la guerra de los malos pensamientos no

12 En su artículo «Quevedo y la sátira de errores comunes», Edad de Oro, II, 1983, 67-82, C. Cuevas García analiza el sentido profundo del romance del fénix, en el cual encuentra «las raíces filosóficas de la sátira de Quevedo, fruto de su escepticismo ante el hombre y su inteligencia» (pág. 78).

13 Sobre la dimensión moral de los emblemas y la función del epigrama en ellos, S. López Poza, «El epigrama en la literatura emblemática española», Analecta Malacitana, XXII, 1, 1999, $27-55$.

14 Sobre el sentido erótico de «delante», «subir»y «bajar», se consultará evidentemente P. Alzieu, R. Jammes e Y. Lissorgues, Poesía erótica del Siglo de Oro, Crítica, Barcelona, 2000. Los autores dan un ejemplo de la expresión «coger delante», traducen «subir» por «salire» y «bajar» por «discedere». Martínez Berbel invita a notar «las numerosas referencias misóginas y las de índole sexual» del romance, y señala que Quevedo «[...] se sirve de la ironía para subvertir el mito, para modificarlo en sus características más internas [...]». J. A. Martínez Berbel, «Algunas calas en el mito de Orfeo y su representación áurea», en M. L. Lobato, F. Domínguez Matito (ed.), Memoria de la palabra. Actas del VI Congreso de la AISO, vol. II, Iberoamericana-Vervuert, Madrid-Frankfurt, 2004, 1277-1287, pág. 1284. 
tiene término» ${ }^{15}$. La reinterpretación de varios de los elementos del relato prepara el epimythium, que anula toda la dimensión amorosa del mito de Orfeo :

Dichoso es cualquier casado

que una vez queda soltero;

mas de una mujer dos veces,

es ya de la dicha extremo.

Lía Schwartz califica a este Orfeo quevediano de «exemplum perfecto del marido afortunado» ${ }^{16}$. El autor pudiera haber aprovechado más la continuación del mito, en particular el desdén de Orfeo hacia las mujeres. Si, para Jáuregui, «El ser amante le reserva y priva / de ser amante» ${ }^{17}$, este repentino desdén pudiera haberse asimilado en la poesía burlesca a una marca de desprecio que, como el comentario que Quevedo hace a la separación de los amantes, entroncara fácilmente con la sátira de las mujeres. La ingeniosa plasmación de una paradoja - la doble viudez es una repetida suerte parece ser lo que motiva el conjunto del poema quevedesco. Por eso la parodia no retoma el mito más allá de la desaparición de Eurídice ${ }^{18}$, y por eso también el locutor no se demora en detalles narrativos o descriptivos.

Otro gran necio por amores es Leandro. Y parece tener motivos similares a los de Orfeo cuando, tras gozar la bella Hero, se encara cada mañana con las aguas revueltas del Helesponto para volver a Abido, y recobrar su libertad. El locutor declara:

$$
\begin{aligned}
& \text { Guarde que le dé } \\
& \text { por cárcel la casa, } \\
& \text { pues son calabozos } \\
& \text { sus mejores salas. }
\end{aligned}
$$

La afirmación está motivada por la torre que, en Sesto, cobija a la virgen Hero, y puede tener calabozos, como cualquier fortaleza. Pero, metafóricamente, los vínculos del amor podrían convertirse para Leandro en calabozos de otro tipo, y Hero le daría la casa por cárcel literalmente, o sea la suya, la torre de Sesto. Por eso el locutor incita a Leandro a huir al amanecer, y lo califica de «arrepentido» (POC, 771, v. 91), dejando

15 Pérez de Moya, op. cit., pág. 520. Se puede leer también una interesante interpretación del mito en Boccaccio, Genealogía de los dioses paganos, ed. M. C. Álvarez y R. M. Iglesias, Editora Nacional, Madrid, 1983, pág. 322.

16 L. Schwartz, «Versiones de Orfeo en la poesía de Quevedo», en De Fray Luis a Quevedo. Lectura de los clásicos antiguos, Universidad de Málaga, 2005, 235-250, pág. 241. Por otra parte, J. Sepúlveda señala en varios poemas de Quevedo el «proceso de reducción del mito a uno solo de sus mitemas, que pasa a asumir en ocasiones valores completamente aislados con respecto a su origen y desvinculados de su desarrollo [...]». J. Sepúlveda, «Erotismo y mitología en la poesía satírico-burlesca de Quevedo», en I. Colón, J. Ponce (ed.), Estudios sobre tradición clásica y mitología, Ediciones Clásicas, Madrid, 2002, 37-51, pág. 41.

17 Jáuregui, Orfeo, vv. 1173-1174 (en Poesía, ed. J. Matas Caballero, Cátedra, Madrid, 1993, pág. 499).

18 Por otra parte, una parodia del mito podía prescindir del episodio homosexual de Orfeo, ya que su difusión en las versiones serias era limitada. 
entender que el personaje mítico se aleja de Hero por el peligro que representa una mujer que podría retenerle a su lado.

Orfeo y Leandro, nos dice el locutor burlesco, fueron dos grandes necios (POC, 765 , v. 16; 771, v. 96). El primero, porque consiguió librarse de su mujer y, no obstante los peligros que representa, bajó a los Infiernos a juntarse con ella. El segundo, porque Hero no era la mujer que Museo pretende sino una moza de ventas, una perla «que a menudo ensartan» aficionada a empinar el codo (vv. 20 y 45-48). El carácter trágico de los dos mitos se esfuma ante estas nuevas verdades. La doble desgracia de Orfeo se convierte en doble suerte ; la muerte de un Leandro que no duda en luchar contra el mar, fiado en el apoyo de Venus, hija del agua y diosa del amor, viene a ser justo castigo de su necedad y falta de criterio. Del mismo modo que la reinterpretación de la «conseja» de Orfeo se concentraba en el epimythium, la última cuarteta del poema de Hero y Leandro insiste en lo que está en juego, revelar la verdad del mito:

$$
\begin{aligned}
& \text { La verdad es ésta, } \\
& \text { que no es patarata, } \\
& \text { aunque más jarifa } \\
& \text { Museo la canta }^{19} \text {. }
\end{aligned}
$$

Museo, según Quevedo, da a lo que no es más que una vulgar patraña el engañoso brillo de un estilo noble. La verdad defendida por Museo es «jarifa», pero falsa. El deíctico «ésta» insiste en que la única verdad del mito de Hero y Leandro es la que acaba de contarse, en virtud de la cual la peligrosa travesía del Helesponto no es una hazaña sino una necedad. En comparación, Góngora sólo pretendía no haber entendido del todo el texto de Museo o no querer perder tiempo con tanto detalle presente en la versión de Boscán. La autoridad de los textos, en Góngora, no se impugna, el locutor no pretende desengañar al lector sino reivindicar una libertad creadora en el distanciamiento con la letra del texto ${ }^{20}$.

Ambos procedimientos, la negación de la verosimilitud del mito o la reinterpretación directa de su sentido, fundamentan la degradación burlesca sobre una preocupación de orden hermenéutico, contestando el mito o su interpretación. La parodia, en cada uno de los tres poemas, es la narración de una historia fabulosa

19 Quevedo, POC, 771, vv. 181-184. A. Carreño comenta : «Quevedo [...] contrasta la historia poética con la mítica, realzando la veracidad de su misma versión, tan cierta como las otras [...]». A. Carreño, «El navegante en "caravana de fuego" : Leandro o la escritura "con letra bastarda" », La Perinola, 6, 2002, 55-72, pág. 69.

20 Góngora «no trata de evadirse de la deuda con el modelo contando otra cosa, modificando el desenlace o añadiendo episodios pegadizos. Todo lo contrario, suele conservar las piezas necesarias para dejar intacta la lógica del relato narrado por la fuente primaria, y para interpretar convincentemente su espíritu». M. Blanco, «Góngora reescritor de ficciones», en G. Grilli (ed.), Modelli Memorie Riscritture, L'Orientale, Napoli, 2001, 309-338, págs. 324-5. 
por parte de un locutor que, antes que todo, quiere declarar que no se la cree. Este me parece ser un punto fundamental para entender la reescritura burlesca de los mitos por Quevedo, y situarla frente a otros autores o parodias de otro tipo, como el Poema heroico de las necedades y locuras de Orlando el enamorado (POC, 875). La reflexión siguiente procurará determinar cuáles son los mecanismos de distanciamiento con las fuentes que marcan la singularidad de la parodia mitológica en Quevedo.

\section{LA RECTIFICACIÓN PARÓDICA O LA INTERPRETACIÓN TRAVIESA DE LAS FÁBULAS MITOLÓGICAS}

El poema de Orfeo retoma los textos de Ovidio y Virgilio sin explayarse en las circunstancias de la muerte de Eurídice ni en las del propio héroe, a manos de las bacantes. La relativa escasez de elementos narrativos es ya un indicio del propósito de Quevedo: el locutor cuenta que Orfeo bajó a los Infiernos por su mujer, que lo hizo cantando y arrastrando tras sí los elementos naturales, que consiguió convencer a «los sordos reinos» de que le devolvieran a Eurídice, a lo cual asintieron con la condición de que no la mirara, compromiso que el héroe no pudo acatar. Este relato ocupa tan sólo ocho cuartetas, e importa subrayar que cada segmento del relato contado da lugar a un comentario, procedimiento comparable con lo que hace Pérez de Moya en sus «declaraciones», y que el travieso mitógrafo creado por Quevedo podría estar parodiando. A la narración detallada se sustituye lo que podríamos denominar la exégesis burlesca de Quevedo.

Este mecanismo del comentario sistemático es un elemento del proceso global de reinterpretación de la fábula, que concluye con las estrofas dedicadas a recalcar la suerte del amante dos veces librado del yugo matrimonial. Aparentemente, Quevedo, al invertir el sentido de cada elemento del relato, modifica el significado profundo de la fábula. Así, por ejemplo, la separación de los amantes, que en Ovidio, Virgilio y luego Boscán es presentada como una repetición de la desgracia que les aflige, se convierte en doble suerte ${ }^{21}$. Pero cabe destacar que las travesuras interpretativas del locutor no siempre estriban en una pura re-invención envilecedora del texto sino a menudo en una lectura orientada de las fuentes y sobre todo, en este caso, de sus comentaristas. Estudiemos, por ejemplo, la procedencia de este Orfeo lujurioso que parece crear Quevedo. En el texto virgiliano, la castidad final de Orfeo («Nulla Venus, non ulli animum flexere hymenaei», v. 516) recuerda la de las abejas, cuya perennidad se logra sin contacto carnal («nec concubitu indulgent nec corpora segnes / in Venerem

21 Virgile, Géorgiques, IV, vv. 495-6 (en Virgile, Géorgiques, ed. E. De Saint-Denis, Les Belles-Lettres, Paris, 1982) ; Ovide, Les Métamorphoses, X, vv. 60 y 64 (en Ovide, Les Métamorphoses, II, Livres VI-X, ed. G. Lafaye, H. Le Bonniec, Les Belles-Lettres, Paris, 2002); Boscán, CXXXI, v. 1525 (en Boscán, Obra completa, ed. Carlos Clavería, Cátedra, Madrid, 1999) ; Quevedo, POC, 765, vv. 37-40. 
soluont», vv. 198-199). La castidad puede aparecer así como una condición de una armonía que, por supuesto, se plasma fundamentalmente en el tema del canto órfico. De hecho, tanto Ovidio como Virgilio insisten en la decisión del héroe de abandonar todo contacto sensual con las mujeres ${ }^{22}$. En Ovidio, no implica una renuncia total a la sensualidad ya que Orfeo enseña a los pueblos de Tracia a amar a los muchachos ${ }^{23}$. Pero esto no aparece ni en Virgilio ni en Boscán ni en Jáuregui. En Boscán, Orfeo se dedica a llorar la muerte de Eurídice, sin que «ningún amor, por blando que viniese, / onesto o desonesto ${ }^{24}$ le desvíe de esta castidad. Jáuregui precisa que «Ni oferta admite, ni caricia siente» ${ }^{25}$. Estas versiones del mito convergen en la elaboración de un Orfeo exclusivamente dedicado al culto de la esposa fallecida, y que no se deja llevar por los reclamos del placer. Ahora bien, la «declaración» de Pérez de Moya destaca también el papel de la sensualidad en el mito de Orfeo:

Por Orpheo se entiende el sabio; por su mujer Eurídice los deseos o apetitos naturales. Toma el sabio a ésta por su mujer por cuanto por sabio que uno sea no puede dejar de tener las concupiscencias, de las cuales en tanto que se vive no podemos ser despojados. [...] Decir que antes que acabase Eurídice de salir del infierno la quiso Orpheo mirar es para declarar que el amor no tiene ley o que la guerra de los malos pensamientos no tiene término. ${ }^{26}$

Según Pérez de Moya, la concupiscencia es responsable de la pérdida de Orfeo, como puede serlo de todos los hombres. Lo que me interesa aquí es el papel que el erudito otorga a la sensualidad en su interpretación del mito, a lo que Virgilio y Ovidio llaman la «Venus». Solía aparecer como algo finalmente rechazado por Orfeo; en Pérez de Moya la sensualidad se convierte en la causa de la pérdida de Eurídice y por lo tanto en un elemento medular. Las versiones poéticas y la exégesis de Pérez de Moya, para un locutor travieso, pueden sugerir que la dicotomía lascivia / castidad es fundamental. Quevedo hace retroceder el papel de la sensualidad en el desarrollo argumentativo de la fábula hasta convertirla en la motivación principal del descenso órfico. Esta interpretación del poema quevediano permitiría explicar, quizás, porqué Orfeo, cuando vuelve la cabeza, no lo hace movido de la concupiscencia. Tras satisfacer sus «apetitos naturales» gozando de Eurídice (o, retomando las palabras del poeta y siguiendo mi línea interpretativa, «subir» e ir «delante»), se separa de ella voluntariamente, o gracias a una casualidad afortunada:

22 Virgilio, loc. cit, v. 516, « Nulla venus, non ulli animum flexere hymenaei »; Ovidio, loc. cit,, vv. 79-81, « omnemque refugerat Orpheus / Femineam Venerem, seu quod male cesserat illi, / sive fidem dederat $»$.

23 Ovidio, op. cit, vv. 83-85.

24 Boscán, op. cit., v. 1544.

25 Jáuregui, op. cit., v. 857.

26 Pérez de Moya, op. cit., págs. 519-520. Ver Martínez Berbel, op. cit. 
Volvió la cabeza el triste:

si fue adrede, fue bien hecho;

si acaso, pues la perdió,

acertó esta vez por yerro.

El fracaso de la empresa del Orfeo mitológico se debía al desarreglo de sus pasiones, y la renuncia al amor sensual parecía la mejor vía para remediar lo que Pérez de Moya llama «la guerra de los malos pensamientos». Para el Orfeo burlesco, el desorden que puede provocar el amor es de otro tipo y por lo tanto el remedio también será distinto. La mujer causa la pérdida del hombre cuando se casa con ella porque, si la viudez es un regreso a la dicha perdida, el matrimonio condena al hombre a una infelicidad consentida. Un parecer idéntico se desprende del análisis del descenso órfico. Lo que, en Pérez de Moya, podía semejarse a una interpretación moral que insistía en la pérdida del hombre provocada por las mujeres ${ }^{27}$, se convierte en una advertencia sobre el peligro que representan, no ya en clave religiosa o moral, sino más bien satírica. Las mujeres causan la pérdida del hombre en el más allá, pero, nos dice Quevedo, el matrimonio también puede convertir esta vida en un infierno. Por eso Orfeo es un necio al tomarse tantas molestias por Eurídice, y por eso hace bien cuando opta por dejarla en los Infiernos. Más que invertir la fábula, lo que hace el español es exagerar un sentido potencialmente presente en el mito original, proponer de él una lectura traviesa nutrida por la tradición satírica. Entre las versiones más patéticas del mito por una parte, $\mathrm{y}$, por otra, el poema quevediano, media la autoridad de los comentaristas renacentistas, que, en cierto modo, encauzan el curso de la interpretación de Quevedo. El poeta aprovecha lo que puede ser útil al locutor travieso en las diversas interpretaciones del mito al mismo tiempo que se distancia de la representación convencional del amante heroico que se atreve a bajar a los Infiernos por amor a Eurídice.

El romancillo Hero y Leandro en paños menores retoma lo que corresponde al momento álgido de la travesía del Helesponto y al trágico desenlace del mito, o sea la catástasis y catástrofe. Desde el punto de vista narrativo, corresponde, pues, al gongorino Arrojóse el mancebito ${ }^{28}$, superándolo en extensión en unos cien versos en

27 No es ésta la opinión de Conti. Considera que Eurídice representa «la justicia y la equidad», y vuelve a los Infiernos para mostrar que «no debe haber un excesivo deseo ni siquiera de la justicia, ya que las perturbaciones del ánimo se aplacan con la razón [...]», Conti, op. cit, pág. 545. Para Conti, y a diferencia de Pérez de Moya, el fracaso de Orfeo se debe a un deseo honesto pero excesivo y que, como tal, debe ser templado. Pero una de las versiones que recoge sobre la muerte de Orfeo cuenta que «después de la muerte de Eurídice, despreció el matrimonio con las restantes mujeres y convenció a muchos hombres de que la mujer es un gran mal, tanto si es mala como si buena [...]» (Conti, op. cit., pág. 543). También pudo esta versión orientar a Quevedo hacia una interpretación satírica del mito.

28 Alatorre considera este poema de Góngora «el primer romance mitológico burlesco que se compuso en España». A. Alatorre, «Los romances de Hero y Leandro», en Libro jubilar de Alfonso Reyes, Universidad Nacional Autónoma de México, 1956, 1-41, pág. 15. 
parte dedicados a la prosopografía de Hero, que Góngora realiza en Aunque entiendo poco griego, y a los comentarios sarcásticos del locutor. La singularidad del texto quevediano radica precisamente en la zumbona descripción de Hero, prosopografía fundamental para entender la nueva interpretación de la fábula, que puede fundarse en una lectura excesivamente traviesa de las fuentes. En el texto de Museo, Hero es una joven doncella encargada del culto de Afrodita, y por lo tanto del amor. Pese a su voto de castidad, no desdeña los amores de Leandro, y los comentarios insidiosos de Museo manifiestan el carácter artificioso y forzado de las protestas de decoro de una Hero que, si es doncella de día, es mujer de noche ${ }^{29}$. En la versión ovidiana, Hero da cuenta de su impaciencia y del ardor de su pasión ${ }^{30}$. De ahí a convertirla en moza de ventas, en una perla que los navegantes «a menudo ensartan», y que en el mismo nombre, Hero, indica en latín que de todos será, sólo había un paso que el pícaro locutor quevediano no duda en franquear. Como tantas mujeres de la poesía burlesca, viene a tributar un homenaje a Venus que, en el caso del personaje de Museo, era predeterminado por su condición de sacerdotisa de Afrodita, como se lo declaraba el propio Leandro con una retórica algo donjuanesca ${ }^{31}$. Hero pasará, en la traviesa interpretación quevediana, a ser «la Hero», o, en palabras de Alatorre, una «Hero-Maritornes» ${ }^{32}$.

En cuanto a Leandro, Museo nos cuenta que Hero le unge con óleos perfumados cuando llega a Sesto para que pierda el olor del mar, y le dice, además, que se olvide del olor del pescado. En el texto de Ovidio, Leandro afirma que de tanto atravesar el Helesponto, los pescados le conocen ${ }^{33}$. Este amante que huele a pescado se convierte

29 Musée, Héro et Léandre, ed. P. Orsini, Les Belles-Lettres, Paris, 2003, vv. 104-108, 130-132, 164-165 y 287.

30 Ovidio, «Hero Leandro», v. 4, «non patienter amo», y vv. 173-174, «Nunc male res junctae, calor et reverentia, pugnant. / Quid sequar, in dubio est ; haec decet, ille juvat», en Ovide, Héroïdes, ed. H. Bornecque, M. Prévost, Les Belles-Lettres, Paris, 1928. En el poema de Boscán, la belleza de Hero es fiel reflejo de la bondad de sus costumbres. Hero asume el amor que siente por Leandro pero teme algún desdoro contra su honra (Boscán, op. cit., CXXXI, vv. 777 y siguientes). Por ello, baraja la posibilidad de ver a Leandro «a hurto» (v. 791). En cierto modo, dicha actitud parece más bien incitar al joven que desanimarle. Además, Hero suscita dudas en Leandro (vv. 246-250, 535-536). Su entrega final («y entrégate de mí, que'stó entregada», v. 2231, «Hero, de l'otra parte, 'stava ardiendo / no pudiendo sufrirse en su deseo», vv. 2563-64) es parte de un conjunto de actitudes que el lector puede analizar como indicios de un deseo que Hero quiere satisfacer. Boscán da argumentos al locutor burlesco, aunque su poema esté inspirado por una concepción del amor y el deseo bien distinta a la del Quevedo de la musa Talía.

31 Museo, op. cit., v. 144 ; la misma fe en el amparo de Venus parece tener su sacerdotisa en Ovide, Heroïdes, «Hero Leandro», vv. 159-160. Boscán, op. cit., CXXXI, vv. 645-646, escribe : «Tú, y las que'stáis a Venus consagradas, / en lecho conjugal havéis de veros».

32 A. Alatorre, « Fortuna varia de un chiste gongorino», NRFH, XV, 1961, 483-504, pág. 488. Susana Guerrero Salazar, op. cit., pág. 34, considera que en la obra de Quevedo «todas las fábulas amorosas con finales trágicos (Hero y Leandro, Píramo y Tisbe, Ifis y Anaxáreta, Orfeo y Eurídice, Apolo y Dafne, etc.), cuando son abordadas desde la perspectiva satírico burlesca, se nos presentan como relaciones prostibularias».

33 Museo, op. cit., vv. 260-271; Ovidio, Héroïdes, «Leander Heroni», v. 132; Boscán, op. cit., CXXXI, vv. 2190-2203. 
naturalmente en «aprendiz de rana», en pescado con escamas. Del mismo modo, la asociación de Leandro con un bajel podría proceder de las fuentes antiguas o de Boscán $^{34}$. Otro detalle, más significativo quizás, que procede de una lectura traviesa del texto original, lo constituye la falta de gregüescos y vestidos del amante de Abido. Es un elemento interesante porque el nadar desnudo de Leandro suscita este comentario de Hero:

$$
\begin{aligned}
& \text { Mas ya que desnudo } \\
& \text { a morir te echabas, } \\
& \text { mucho tus vestidos } \\
& \text { hoy me consolaran }{ }^{35} \text {. }
\end{aligned}
$$

Esta Hero entronca mediante tales palabras con otra figura familiar de la poesía burlesca. Además de moza de ventas aficionada a los marineros y a vaciar cueros, es una pedigüeña. El detalle de la desnudez de Leandro está presente en Ovidio de manera repetida ${ }^{36}$, y contradice el modelo aducido por Quevedo, Museo ${ }^{37}$. En el poema griego, Leandro se quita la ropa pero se la lleva en la travesía, detalle que retomará Boscán $^{38}$ y que ilustra también un grabado presente en la versión paródica de Scarron ${ }^{39}$. Quevedo pudo inspirarse directamente en Ovidio, pero también en Góngora («Ya se va dejando atrás / las pedorreras azules ${ }^{40}$ ) o Pérez de Moya, quien asocia la desnudez de Leandro al desamparo en que puede encontrarse el amante ${ }^{41}$. Aprovecha un detalle

34 Ovide, Héroïdes, «Leander Heroni», vv. 148 y 215 ; Museo, op. cit., vv. 211-212, 255 ; Boscán, op. cit., CXXXI, vv. 878-879. Consultar Alatorre, «Los romances de Hero y Leandro», pág. 4. Nótese que la comparación con un bajel también aparece en las versiones graves que Quevedo hizo del mito (POC, 210, v. 7 y 311, v. 9). Pero es de otro cuño en el romancillo, ya que el locutor increpa a Leandro y cuestiona el excesivo orgullo que le hizo pensar que podría realizar lo que sólo puede hacer un bajel o un pez («i Qué imagina cuando / de bajel se zarpa, / hecho por la Hero / aprendiz de rana? », POC, 771, vv. 5-8). Lo que, en la poesía grave, es señal de heroísmo varonil, se convierte en la poesía burlesca en indicio de una hybris que merece ser castigada porque por ella el individuo pretende elevarse al rango de héroe. Alatorre, loc. cit., págs. 29-32, compara las dos versiones.

35 Quevedo, POC, 771, vv. 133-136. También, v. 65.

36 Ovide, Heroïdes, «Leander Heroni», vv. 33-34, 57, y sobre todo «Hero Leandro», vv. 43 y 61.

37 V. Cristóbal López, « Hero y Leandro », en Amores míticos, ed. E. Fernández de Mier, Félix Piñero, Ediciones Clásicas, Madrid, 1999, 195-221, pág. 210, señaló esta discrepancia entre Ovidio y Museo.

38 Museo, op. cit., v. 252 ; Boscán, op. cit., CXXXI, vv. 2113-2114, aunque este detalle no reaparece en el v. 2729.

39 El grabado puede consultarse en R. Picard, La Poésie française de 1640 à 1680. Satire. Épître. Burlesque. Poésie galante, SEDES, Paris, 1969, pág. 85

40 Góngora, «Arrojóse el mancebito», vv. 5-6, y también en «Aunque entiendo poco griego», v. 189 (en Góngora, Obras Completas, I, ed. A. Carreira, Biblioteca Castro, Madrid, 2000, págs. 111 y 315).

41 "Nada desnudo, porque el amor sabe desnudar a los que le siguen y arrojarlos en los peligros [...]", Pérez de Moya, op. cit., pág. 587. «[...] éste es su truco [...] para no tener que pagar a la prostituta, pues no tiene donde llevar el dinero [...] En esta versión burlesca del mito (Leandro que va desnudo al encuentro con Hero) está la clave para combatir el robo de las prostitutas hacia sus clientes, pues si todos fueran desnudos, aunque las prostitutas hicieran de sus uñas tenazas, no podrían despojarlos de sus pertenencias [...]», S. Guerrero Salazar, op. cit., pág. 355, y págs. 347-363 para un comentario pormenorizado de este poema de Hero y Leandro. 
para conseguir que el relato fuente entronque con el propósito de la parodia, degradar lo suficientemente a Hero como para convertir el sentimiento amoroso de Leandro en un desvarío, y los riesgos a los cuales se expone en un indicio de su necedad. El exponerse a tantos peligros por satisfacer su lujuria redunda en su desprestigio, como pasaba en el caso del necio Orfeo. Por eso, el locutor puede regodearse con comentarios sumamente sarcásticos, preguntando por ejemplo a un Leandro zarandeado por las olas si se ahoga de veras o si juega al escondite. El dramatismo de la escena se esfuma a favor de un humor negro que zahiere al amante culpable de poner su vida en peligro por un sentimiento tan desdeñable como el amor a una mujer de la calaña de «la Hero». Como comenta Susana Guerrero Salazar, Quevedo «elimina de raíz toda la ternura y el idealismo que había en la historia de estos amantes y nos proporciona una caricatura extrema del amor y de la mujer» ${ }^{42}$. Las amplificaciones que describen a la moza de Sesto y comentan la acción sirven de base a la reinterpretación del sentido de la fábula, que ya no constituye una tragedia del amor sino un poema sobre la necedad de los enamorados ${ }^{43}$. De ahí la diferencia de tonalidad entre Quevedo y Góngora: el locutor gongorino considera la muerte de Leandro como una tragedia, un mito cuyo significado no varía: el amor acarrea tragedias, y ésas son el signo del verdadero amor. Por ello, la parodia versa fundamentalmente en una degradación que no pone en tela de juicio la legitimidad del amor de Leandro. La distanciación con el epilio cuaja, por ejemplo, en la caracterización del locutor ${ }^{44}$, de las adversas circunstancias climáticas («se desatacó la noche, / y se orinaron las nubes» ${ }^{45}$ ), en la descripción del galanteo de un Leandro soez, «ventor por el cabo», a quien se le cae literalmente la baba ante $\mathrm{Hero}^{46}$, y que pía, cacarea, arrulla y hace ruedas cual ave de corral. Por ello, también, Góngora hace de Hero una mujer de suma belleza, que justifica el sacrificio de Leandro $^{47}$. Nótese, por ejemplo, que las alusiones escatológicas por las cuales Quevedo

42 S. Guerrero Salazar, op. cit., pág. 349.

43 En POC, 768, los ejemplos míticos de Hero y Leandro, Píramo y Tisbe, Hércules,... sirven para desmentir el título de la comedia para la cual este romance debe servir de loa: «Amor y celos hacen discretos».

44 Además de la alusión escatológica a los versos «ni muy duros, ni muy blandos» encontrados por el locutor en sus gregüescos, la degradación de la situación enunciativa pasa por la asunción de un conocimiento y una comprensión restringidos del texto griego (Góngora, «Aunque entiendo poco griego», vv. 1-4 y 61-70). Esta postura del locutor ante los hechos narrados también la encontramos en Scarron, op. cit., págs. 90-91, vv. 205-206 y 217-224. G. Lanson, «Etudes sur les rapports de la littérature française et de la littérature espagnole au XVIIè siècle (1600-1660). Góngora ", Revue d'Histoire littéraire de la France, III, 1896, 321-331, coteja los textos de Scarron y Góngora para resaltar la deuda contraída por el francés. También Moya del Baño, El tema de Hero y Leandro en la literatura española, Publicaciones de la Universidad de Murcia, 1966, págs. 102-106.

45 Góngora, «Arrojóse el mancebito», vv. 15-16.

46 Góngora, «Aunque entiendo poco griego», vv. 40 y 101-104.

47 Alatorre, «Los romances de Hero y Leandro», pág. 30, compara el poema de Góngora con el de Quevedo: «Si el "castillo" es ahora mesón inmundo, también Hero, mozuela coqueta en Góngora, es ahora una daifa repugnante ; su retrato era allá irónico, pero depurado y exquisito ("lo torneado del cuello / y 
degrada la figura de $\mathrm{Hero}^{48}$ nunca afectan al personaje gongorino. Si las lágrimas que se desprenden de la cara de la Hero quevedesca acarrean una comparación con las mujeres que vacían las inmundicias, las del personaje gongorino son «dos mil perlas» ${ }^{49}$. La descriptio puellae en Aunque entiendo poco griego es radicalmente diferente de la que realiza Quevedo. El lirismo del vate cordobés se suma a un dramatismo que marca también una concepción distinta de la parodia. Léanse al respecto estas dos cuartetas, cuyos paralelismos sintácticos, bimembraciones y anáforas parecen imitar el vaivén de las aguas que anegan a Leandro:

$$
\begin{aligned}
& \text { El amador, en perdiendo } \\
& \text { el farol que lo conduce, } \\
& \text { menos nada y más trabaja, } \\
& \text { más teme y menos presume; } \\
& \text { ya tiene menos vigor, } \\
& \text { ya más veces se zabulle, } \\
& \text { ya ve en el agua la muerte, } \\
& \text { ya se acaba, ya se hunde }{ }^{50} \text {. }
\end{aligned}
$$

El locutor incita al lector a una actitud compasiva ante los apuros del héroe. Un simple cotejo de la versión gongorina con la de Quevedo basta para advertir las diferencias en el proceso paródico:

$$
\begin{aligned}
& \text { ¿Juega al escondite? } \\
& \text { Si danza, sea la Alta: } \\
& \text { que en el mar no es bueno } \\
& \text { el danzar la Baja. }{ }^{51}
\end{aligned}
$$

\begin{tabular}{l}
\hline del pecho el alabastro..."); aquí es caricatura horrenda ("piernas de ramplón / fornida de panza...") ». R. \\
Jammes, La obra poética de Don Luis de Góngora y Argote, Madrid, Castalia, 1987, págs. 132-136, estudia la \\
parodia gongorina del mito de Hero y Leandro. Sus comentarios recalcan la belleza de Hero («Góngora \\
describe una belleza real que no tiene nada que envidiar a las múltiples siluetas femeninas evocadas \\
en su poesía no burlesca»). Robert Jammes considera que «el autor no es indiferente a la tragedia que \\
cuenta». Compartimos plenamente su análisis.
\end{tabular}

48 Guerrero Salazar, op. cit., págs. 361-362, comenta el suicidio de Hero y puntualiza los elementos escatológicos que conviene reconocer en los versos 165-180. Ver también A. Carreño, op. cit.

49 Góngora, «Arrojóse el mancebito», v. 42.

50 Góngora, «Arrojóse el mancebito», vv. 49-56.

51 R. Morales Raya, «Cronología de dos parodias áureas del mito de Hero y Leandro», Edad de Oro, XIII, 1994, 103-112, págs. 106-107, considera que estos versos de Quevedo se inspiran en los vv. 25-28 de «Arrojóse el mancebito». Este artículo renueva el panorama de las relaciones entre los dos romances de Góngora y los dos poemas de Quevedo. Postula que « Señor don Leandro » se inspira en el gongorino "Arrojóse el mancebito", pero que, a su vez, influyó en la redacción de «Aunque entiendo poco griego». Por otra parte, Morales Raya señala el patetismo de «Arrojóse el mancebito», declarando que «la impresión última que obtiene el lector es de burlesca con fondos en cierta gravedad». En comparación, Quevedo acentúa «los rasgos novedosos, es decir la burla y el sarcasmo, hasta límites tan extremos como llegar a caracterizar a la protagonista de moza alegre de venta, de apariencia repulsiva, y a Leandro de jayán necio que imprudentemente se arroja a la mortal travesía por ver a su daifa, del todo inmerecedora de semejante temeridad» (pág. 105). 


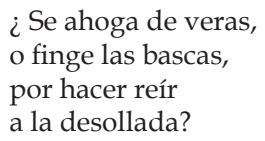

El relato dramático se convierte en comentario escarnecedor, los elementos líricos se hacen satíricos ${ }^{52}$. La reescritura mitológica en Góngora no implica, en el caso del mito de Hero y Leandro, una reinterpretación del sentido de la fábula, lo que sí constituye el meollo del proyecto quevedesco. Góngora permanece más fiel al sentido y al tono de los textos de Ovidio, Museo y Boscán. En líneas generales, podríamos decir que Quevedo reintepreta el mito sin preocuparse por la narración, mientras que Góngora lo narra sin reinterpretar lo que, en última instancia, puede significar. Para Quevedo, el mito de Leandro y Hero, tal y como lo cuentan las fuentes antiguas, no es más que la sublimación literaria de una de tantas historias de pedigüeñas y amante bobo. Orfeo y Leandro ejemplifican la necedad a la que el amor puede llevar los amantes.

Esta preeminencia dada a la declaración de la verdad del mito justifica el carácter más descriptivo que narrativo de Hero y Leandro en paños menores ${ }^{53}$, y la tendencia al comentario sistemático en ambos poemas. No hace falta demorarse en el relato de unos sucesos de sobra conocidos por el lector, ya que poca importancia tienen para entender cabalmente la acción. Lo que sí encauza la interpretación burlesca de los mitos por parte de Quevedo, es el postulado que algo no se entendió o que un elemento faltó a quienes procuraron entender la fábula. En este sentido, la parodia mitológica es también burla de quienes se empeñan en aclarar el sentido de los mitos $^{54}$. No comprendieron que Orfeo volvió la cabeza para separarse de su mujer y que Leandro, arrepentido (POC, 771, v. 91), regresaba a Abido para no quedarse con la suya. La reescritura pasa, pues, por lo que llamaba antes una exégesis burlesca, una sistematización de

52 J. Iffland, Quevedo and the grotesque, II, Tamesis Books, Londres, 1983, págs. 153-159, estudia el humor negro del poema. Guerrero Salazar, op. cit., pág. 357 considera que «[...] la ausencia de dramatismo es absoluta, toda la escena es burlesca [...]».

53 Comparando las parodias que Quevedo y Góngora realizan del mito de Hero y Leandro, Franco Durán declara: «A través de alusiones a diversos refranes y metáforas despectivas, interrogaciones retóricas y lenguaje vulgar, el autor [Quevedo] acelera el ritmo del romance, mucho más narrativo en Góngora, y nos ofrece una versión escéptica para llegar a la máxima deformación en el tratamiento de los modelos antiguos», en M. J. Franco Durán, «El mito de Hero y Leandro : algunas fuentes grecolatinas y su pervivencia en el siglo de oro español», Verba Hispanica, IV, 1994, 65-82, pág. 78. Sobre la poética de la parodia, ver Carreño, op. cit.

54 Sagrario López Poza mostró que, si bien para ser humanista Baltasar de Céspedes consideraba que había que saber explicar los sentidos de las fábulas, Quevedo «rechaza voluntariamente la declaración de fábulas y sólo trata de ellas en forma de irónico contrafactum» (S. López Poza, «Quevedo, humanista cristiano", en Quevedo a nueva luz: escritura y política, ed. L. Schwartz, A. Carreira, Universidad de Málaga, 1997, 59-81, pág. 68). 
los comentarios ${ }^{55}$, que pueden cobrar formas diversas. Importa notar al respecto que, al dedicar los primeros versos de Hero y Leandro en paños menores a maldecir al mozo («Señor don Leandro / vaya en hora mala»), el poeta pergeña el perfil de un locutor insolente. Por ello, el lector atribuye muchos versos narrativos al comentario más bien que a la propia narración. Algo así ocurre cuando el locutor guasón afirma que Hero «hace camas bien / y deshace camas», que nadie murió ahogado con tanta gracia como Leandro (vv. 117-120), o que las olas se apartan para no mancharse al tirarse Hero por la ventana (vv. 167-68).

Del modelo a su contrafactum burlesco no se modifica sustancialmente la concatenación de los acontecimientos que vertebran la fábula sino su caracterización e interpretación, las «veras» que se entremezclan entre tantas burlas. La fábula da pie a una reinterpretación distinta del sentido original y que estaba a la vista de un lector travieso y dispuesto a considerar el repentino amor de Hero como una prueba de liviandad, y el rechazo órfico de las mujeres como una justificación mítica del odio que suscitan $^{56}$. La verdad de estos poemas siempre es la misma, en consonancia con el conjunto de la poesía burlesca de Quevedo: el amor es una necedad, las mujeres causan la pérdida de los hombres, y ninguna de ellas es tan pura como pretenden los mitos. Por ello, en otro soneto de Quevedo, Júpiter debería pagar a Dafne en lugar de perseguirla. Procede resaltar, pues, la coherencia de las técnicas de parodia mitológica en Quevedo y la perfecta integración de los héroes degradados en el infra-mundo burlesco.

\section{LOS VARIOS CAMINOS DE LA RENOVACIÓN PARÓDICA}

Algunos mecanismos paródicos se repiten en las fábulas mitológicas burlescas del Siglo de Oro. Además de los numerosos procedimientos lingüústicos ${ }^{57}$, como la sufijación degradante, citemos por ejemplo el anacronismo, la humanización de los comportamientos divinos en una relectura inesperada del evemerismo, o la introducción

55 Esta importancia otorgada a los comentarios del locutor me lleva a considerar que Califica a Orfeo para idea de maridos dichosos y Hero y Leandro en paños menores deberían integrar preferentemente el tercero de los cinco modelos de fábulas burlescas propuestos por José Lara Garrido. En él, «[...] la conservación de la forma narrativa propicia un proceso desmitificador peculiar en el que en el plano del asunto el mito se reduce a un mínimo esquema y el narrador introduce el comentario burlesco en cada componente». J. Lara Garrido, «Consideraciones sobre la fábula burlesca en la Poesía Barroca. (A propósito de una versión inédita de la de "Apolo y Dafne")», Revista de Investigación. Filología, Soria, 1983, 21-42, pág. 26.

56 Un procedimiento comparable se encuentra en el soneto 560, basado en el grabado del emblema 160 de Alciato. El cojo y el ciego que se ayudan mutuamente en el emblema se convierten en prueba de «la interesable correspondencia de la vida humana». Los hombres no se ayudan por caridad sino por maña, $\mathrm{y}$ «todo este mundo es trueco interesado».

57 Guerrero Salazar, op. cit., dedica las páginas 107-205 a los «Principales mecanismos léxicos en la parodia quevediana de los mitos». 
de un episodio completamente nuevo. Este último mecanismo se encuentra, por ejemplo, en la Fábula del Fénix de Pantaleón de Ribera. El poeta imagina un encuentro entre su personaje y el ave mítica. Es suficiente para renovar hábilmente un discurso sobre la que se consideraba rara avis. Entre los numerosos mecanismos de la parodia es interesante señalar, también, la fuerza de inercia que tienen algunos motivos a menudo asociados a la sátira, como los cuernos o la peligrosidad de los médicos. Por ejemplo, en el epitafio que Castillo Solórzano imagina en la tumba de Acteón, no puede evitar un chiste basado sobre los cuernos del mozo convertido en ciervo :

$$
\begin{aligned}
& \text { De tierra ocupa diez pies, } \\
& \text { quien solo ocupara siete, } \\
& \text { si las ramas del copete } \\
& \text { no le acrecentaran tres: } \\
& \text { caminante aunque le ves } \\
& \text { de armazones coronado, } \\
& \text { no pienses que fue casado, } \\
& \text { porque si casado fuera, } \\
& \text { muy rico y viejo viviera, } \\
& \text { no moço y aperreado. }{ }^{58}
\end{aligned}
$$

A Quevedo le viene de perlas tan manido motivo cuando trata del Unicornio. Del mismo modo, recurre a la pésima fama de los médicos para renovar el discurso sobre la perpetua muerte del Fénix ${ }^{59}$ y el poder letal del Basilisco. Quiero apuntar, de paso, que la introducción de estos motivos ajenos a la diégesis del mito es un indicio del valor que les otorga el locutor: sabe que el lector asocia inmediatamente el cuerno al cornudo y el médico a la muerte; resulta muy fácil, pues, crear un chiste basado en dichos motivos. El locutor hace alarde de su habilidad para vincular con gracia dos motivos que aparentemente tienen poco en común. La introducción de estos motivos en contextos mitológicos muestra cómo su potencial satírico se reduce a la mínima expresión a favor de un juego conceptista bastante inocuo. Inocuo para el médico y el cornudo, pero no para el Fénix o el Basilisco. Porque el locutor, mediante este discurso que opone el mundo de los mitos y el de las realia (médicos y cornudos), insinúa que el primero es pura mentira. Además de mentirosos, el locutor parece considerar que los mitos constituyen un material que da un margen demasiado limitado a la creación poética. Los mitos dan lugar a interpretaciones invariables. Por ello dice de la Fénix:

$$
\begin{aligned}
& \text { ansí de cansarte dejen } \\
& \text { similitudes prolijas, } \\
& \text { que de lisonja en lisonja } \\
& \text { te apodan y te fatigan. }
\end{aligned}
$$

y del Pelícano:

58 A. de Castillo Solórzano, Donayres del Parnaso, Madrid, Diego Flamenco, 1624, ff. 27v.-28r.

59 Guerrero Salazar, op. cit., pág. 43. 
Que no entrarás en mis coplas

te lo juro a Jesucristo:

que yo no doy alabanza

a quien no clavo colmillo ${ }^{60}$.

Lo que el locutor quevedesco propone es una alternativa al discurso grave suscitado por mitología y paradoxografía, asociado en el romance del Unicornio a los poetas que se sitúan en la estela del cultismo:

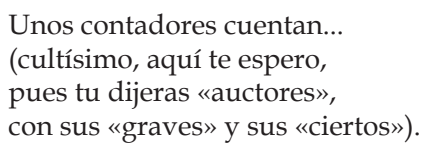

Susana Guerrero Salazar declara que en Quevedo «la burla del lenguaje poético de Góngora suele incluir con frecuencia la mofa de signos míticos» ${ }^{61}$. En este romance, el poeta «cultísimo» es el que, en una fábula sobre el Unicornio, calificaría a sus «auctores» de «graves» y «ciertos». La burla afecta al tratamiento poético que el cultismo hace de la mitología. A esta presentación seria de los mitos el locutor opone un lenguaje que pretende desprovisto de artificio. Introduce su relato con fórmulas como «Unos contadores cuentan», o «diz que dicen», que contrastan con el registro atribuido al cultismo, procedimiento al que Quevedo recurre también en Búrlase de todo estilo afectado (POC, 672). Evidentemente, Quevedo reduce aquí el cultismo a su dimensión grave, omitiendo tanta parodia burlesca como la que suscitó Góngora, en particular a partir de la Tisbe ${ }^{62}$. El locutor burlesco se rebela ante la sistematización de las interpretaciones de los grandes mitos. Él opta por un tratamiento descarado, un contrafactum risueño que escarnece tanto el mito como los poetas que lo cuentan. Así puede afirmar de las dotes de vate atribuidas a Orfeo:

Montañas, riscos y piedras
su armonía iban siguiendo;
y si cantara muy mal,
le sucediera lo mesmo

60 Interpreto esta cuarteta de la siguiente manera : no doy alabanza a las aves que no existen y que por lo tanto no puedo comer («clavar colmillo») ; no doy alabanza a los motivos que sólo pueden suscitar un discurso consabido sobre sus virtudes y que, por lo tanto, no puedo tratar de burlas («clavar colmillo»).

61 Guerrero Salazar, op. cit., pág. 76, y, en general, el capítulo «El mito en la sátira del lenguaje y de los tópicos literarios», págs. 74-91.

62 Acerca del epilio burlesco, de la influencia de Góngora y de su «Fábula de Píramo y Tisbe», escribe Jesús Ponce: «Con esta última gran pieza culminaba un proceso de renovación barroca, cuyo eje es la fusión de burlas y veras, cuestión capital para una poética revolucionaria que permitiría a los textos ir más allá de los estrechos límites de la parodia» (J. Ponce Cárdenas, Góngora y la poesía culta del siglo XVII, Ediciones del Laberinto, Madrid, 2001, pág. 35).

63 S. Guerrero Salazar, Las fábulas mitológicas en Francisco de Quevedo, Universidad de Málaga, Tesis Doctorales-Microficha núm. 228, 1998, pág. 520, interpreta así esta estrofa: «El poder órfico del canto se destruye, pues el movimiento de la naturaleza no se interpreta como un efecto de la armonía, pues 
La figura del poeta sale bastante mal parada, y esto forma parte de un discurso que entronca con los ataques dirigidos al poeta «cultísimo», y que también aparecen, en prosa, en las Premáticas del Desengaño contra los poetas güeros ${ }^{64}$. Esta concepción del relato fabuloso grave, que lo asocia a un discurso que, de tanto repetirse, viene a perder su sentido, a convertirse, como los refranes o los tópicos del petrarquismo, en un lugar común, creo que explica porque la parodia de Quevedo pasa ante todo por la reinterpretación de la verdad del mito ${ }^{65}$. La preocupación hermenéutica entraña otra, de orden estético. Y esto parece confirmado por la comparación con la gran obra paródica de la poesía de Quevedo, el Poema Heroico de las necedades y locuras de Orlando el enamorado, que, como dijo Luzán, «quedó solamente empezado, con harto sentimiento de las Musas ${ }^{66}$. Aquí, no hay reinterpretación del romanzo de Boiardo, y Quevedo propone un tipo de parodia distinto del que realizó en los poemas de Hero y Leandro u Orfeo. Sólo me referiré a dos amplificaciones del primer canto. Cuando Quevedo relata la entrada de Angélica, inmediatamente anterior al parlamento que dirige a Carlomagno, se demora en la descripción de la princesa del Catay. Del cotejo con el texto de Boiardo, que Malfatti cita en nota, se deduce que en este episodio Quevedo retoma sobre todo del italiano las reacciones provocadas por Angélica sobre los paladines. La amplificatio que retrata a Angélica es, por lo tanto, una interpolación de Quevedo orientada a celebrar jocosamente su deslumbrante belleza (I, vv. 431-512, Malfatti, págs. 70-73). Asimismo, la descripción del Padrón del Pino (I, vv. 721-824, Malfatti, págs. 8083) nada debe a Boiardo. Pues bien, esos dos episodios tienen un carácter descriptivo de signo opuesto a lo que leíamos en la parodia quevedesca de las fábulas mitológicas. Angélica y el Padrón del Pino simbolizan lo que Dámaso Alonso llamaba «el mundo de las bellas representaciones ${ }^{67}$. El sentido de la parodia no nace de la mera inversión del romanzo boiardesco sino de la confrontación de dos mundos que no consiguen hacer mella el uno en el otro. Quevedo pudiera haber convertido a Angélica en una moza fea,

aunque Orfeo cantara mal, las montañas, riscos y piedras bailarían contagiados por su alegría ante la pérdida de la mujer». Comenta este poema en las págs. 519-522. Efectivamente, el poder del canto se destruye, Orfeo se nos aparece como un poeta del montón, sin poderes mágicos. Eso es lo esencial en esta cuarteta que ataca a Orfeo como arquetipo del poeta. Los dos últimos versos podrían significar que, si cantara mal, se le tiraría piedras (e incluso, hiperbólicamente, riscos y hasta montañas).

64 «Y últimamente, a todos los poetas en común les mandamos descartar de Apolo, Júpiter, Saturno y otros dioses, so pena que los ternán por abogados a la hora de su muerte». Quevedo, Premáticas del Desengaño contra los poetas güeros, en Obras completas en prosa, Volumen I, tomo I, ed. A. Azaustre Galiana, Castalia, Madrid, 2003, pág. 17.

65 Quevedo «persigue la desautomatización de todo tipo de convenciones, entre ellas, las fábulas mitológicas [...] A fin de romper con el tópico literario que recurría a los dioses del Olimpo para dar muestra de erudición, moralidad, etc., Quevedo construye la parodia de las divinidades y de sus fábulas, mezclando los registros lingüísticos más diversos», S. Guerrero Salazar, La parodia quevediana de los mitos, pág. 149.

66 I. de Luzán, La Poética o reglas de la poesía en general y de sus principales especies (ediciones de 1737 y 1789), ed. Isabel M. Cid, Cátedra, Madrid, 1974, pág. 238.

67 D. Alonso, Poesía española. Ensayo de métodos y límites estilísticos, Gredos, Madrid, 1993, pág. 541. 
a imagen y semejanza de «la Hero», pero prefiere utilizarla como uno de los elementos que, en su parodia, establecerán un marcado contraste con el universo del furor y la lujuria, simbolizado por Ferragut. La locura de los paladines, provocada por Angélica, acarrea el desorden, el caos, conforme con los planes del padre de Angélica. La corte del emperador no entiende que esto forma parte del plan del rey del Catay. Por eso los caballeros embelesados por Angélica son, además de locos de amor, necios. Pero, del mismo modo que en Aunque entiendo poco griego, el locutor celebra la belleza de la princesa y, por lo tanto, explica el comportamiento de los enamorados. En este sentido, Quevedo, en el Poema Heroico, no re-interpreta el romanzo, no modifica radicalmente los motivos de los personajes y la lógica de los sucesos. Su concepción de la parodia, en este caso, se parece más a la del Góngora de Aunque entiendo poco griego, con su tan lograda mezcla de burlas y veras, de lo cómico con lo trágico. Malfatti, en su estudio, resaltó la influencia del culteranismo que evidencian los versos del Poema Heroico de las necedades y locuras de Orlando el enamorado. Afirmó que entre los poetas que influyeron en su redacción «no cabe excluir a Góngora, especialmente a (sic) Góngora del Polifemo» ${ }^{68}$. Pero creo que a Góngora debe algo más que una tendencia al culteranismo, aprendido quizás en sus parodias de los mitos de Hero y Leandro o en la más tardía de Píramo y Tisbe : una concepción de la parodia más orientada hacia la deformación de la fábula que hacia su reinterpretación, una preocupación por la confrontación de la belleza y la fealdad, la luz y la oscuridad, los niveles estilísticos ${ }^{69}$, en virtud de la cual poco importa lo que puede significar, en última instancia, la fábula contada. Este distinto estatuto otorgado a la «verdad» de la historia está determinado, precisamente, por la varia fortuna de los relatos contados. Los mitos de Hero y Leandro u Orfeo pueden contarse de maneras diversas, pero al fin y al cabo siempre significan lo mismo. Otro tanto pasa con el Fénix, el Pelícano, el Basilisco o el Unicornio. La parodia versará, por lo tanto, en una anulación o una renovación de su sentido. En cambio, y aunque la literatura caballeresca esté en crisis a principios del XVII y se preste a la parodia, no da lugar a interpretaciones que procurarían sistematizar su sentido. El contrafactum descansará, por lo tanto, en una deformación del relato inicial que nos presente a los personajes como con una lupa, transformando a la linda Angélica en un prodigio de

68 Quevedo, Poema heroico de las necedades y locuras de Orlando el enamorado, ed. M. Malfatti, Sociedad Alianz de Artes Gráficas, Barcelona, 1964, págs. 35-47. La cita en pág. 43.

69 S. Guerrero Salazar, La parodia quevediana de los mitos, págs. 347-363, en su comentario del poema de Hero y Leandro, señala la mezcla de los registros léxicos. Acerca del Poema Heroico..., afirma que allí Quevedo «lleva a su máxima expresión la técnica del grotesco, porque entrecruza el estilo elevado con el grosero. Es en el estilo culto, presente especialmente en la descripción de la belleza de Angélica y del paisaje, donde se introducen las citas mitológicas» (ibid., pág. 147). En el Poema Heroico..., el mecanismo es masivo y, sobre todo, forma parte de un proceso global de confrontación de fealdad y belleza que, llevado a las cuotas que tiene, hace la singularidad de esta parodia en el corpus burlesco quevediano. Quizás sea Angélica el personaje más importante para interpretar cabalmente lo que hace la singularidad de esta obra. 
belleza o al enajenado Ferragut en un portento de furor libidinoso, pero sin modificar profundamente la interpretación que supone el texto.

Desde el punto de vista narrativo, el Poema Heroico de las necedades y locuras de Orlando el enamorado es una parodia mucho más lograda que Califica a Orfeo para idea de maridos dichosos o Hero y Leandro en paños menores. El lector sigue con ganas el transcurrir del relato renacentista, con sus variaciones estilísticas que califican a Angélica de «inmensa luz» o de «chicota», con su ritmo arrollador que nos transporta de la Corte del Emperador al Padrón del Pino, con su dinamismo tanto vertical, el de las alturas de los gigantes de Angélica o de los demonios de Malgesí, como horizontal, mediante por ejemplo las carreras de Astolfo o Argalía al embestir a Ferragut. No así las parodias de fábulas mitológicas, en las cuales Quevedo se complace en ensartar comentarios sarcásticos del gusto del lector de poesía burlesca, pero que desde luego no seducirán tanto al que busque el placer que proporciona un relato contado con habilidad narrativa ${ }^{70}$.

Las parodias mitológicas de Quevedo manifiestan una preocupación que podría ampliarse a muchas más composiciones, tanto en verso como en prosa. Lo que revelan los poemas de Hero y Leandro u Orfeo acerca de los mitos, así como la burla de la «linda recancanilla» de la poesía amorosa ${ }^{71}$ o el escarnio del uso incontrolado de los refranes y frases hechas en el Cuento de cuentos, es un mismo proyecto de poner en solfa un uso sistematizado y aparentemente incontrolado del lenguaje que termina por vaciarlo de su sentido. Por ello, procede leer las parodias mitológicas de Quevedo como una apuesta por la renovación de las fábulas mediante su reinterpretación, la propuesta de una alternativa lúdica que obligue al lector a compartir las travesuras interpretativas del poeta burlesco, contribuyendo así a la perennidad de estos motivos como fuente de creación poética.

70 Por otra parte, el método de la reinterpretación del mito impone límites a la coherencia de la parodia. Para mantenerse fiel a la catástrofe final del mito, Quevedo hace que Hero se suicide. Pero esta prueba de amor resulta algo extraña al lector que acaba de leer un poema sobre una prostituta «que a menudo ensartan», y cuya primera reacción, nada más ahogarse Leandro, es lamentar que no pueda al menos obtener de él algo de ropa. Además, en el epitafio final tampoco parece muy lógico que Hero, antes de echarse al vacío, considere que su amor por Leandro sea tal que merezcan ser tachados de «tonto» $\mathrm{y}$ «mentecata» (nótese que el epitafio lo imagina Hero, atribuyéndolo al dios Amor). En Góngora, la calificación de «no menos necios que ilustres» («Arrojóse el mancebito», v. 86) la asume oportunamente la criada. Además, el amor de los dos amantes no está en tela de juicio, y la fidelidad a los relatos que cuentan el suicidio final no plantea problemas. En este sentido, Góngora se muestra mucho más cuidadoso de la lógica de su poema.

71 POC, 672. 